\title{
LIFE SATISFACTION AND RISK OF BURNOUT AMONG MEN AND WOMEN WORKING AS PHYSIOTHERAPISTS
}

\section{ZBIGNIEW ŚLIWIŃSKI I,2, MAŁGORZATA STARCZYŃSKA ${ }^{1}$, IRENEUSZ KOTELA ${ }^{1,3}$, TOMASZ KOWALSKI ${ }^{3}$, KAROLINA KRYŚ-NOSZCZYK ${ }^{4}$, DANUTA LIETZ-KIJAK ${ }^{5}$, EDWARD KIJAK ${ }^{6}$, and MARTA MAKARA-STUDZIŃSKA ${ }^{4}$}

\author{
${ }^{1}$ Jan Kochanowski University, Kielce, Poland \\ Institute of Physiotherapy \\ ${ }^{2}$ Physiotherapy Center, Zgorzelec, Poland \\ Department of Orthopedics and Traumatology \\ ${ }^{4}$ Medical University of Lublin, Lublin, Poland \\ Department of Applied Psychology \\ ${ }^{5}$ Pomeranian Medical University, Szczecin, Poland \\ Department of Dental Physicodiagnostics and Propedeutics \\ ${ }^{6}$ Pomeranian Medical University, Szczecin, Poland \\ Department of Prosthodontics
}

${ }^{3}$ Central Clinical Hospital of Ministry of Internal Affairs, Warszawa, Poland

\begin{abstract}
Objectives: Recently in Poland as a result of the high rate of aging population and high rates of morbidity, a growing demand for the physiotherapist profession is observed. The results of this study can be used to formulate principles for better organization of physiotherapist's workplace in order to prevent occurrence of burnout. The aim of this study is to investigate the effect of gender on satisfaction with life and burnout among active physiotherapists. Material and Methods: The survey was anonymous and voluntary, and involved a group of 200 active physiotherapists working in health care units and educational centers in Poland. The study group was selected randomly and incidentally. Each respondent received a demographic data sheet and a set of self-rating questionnaires (Life Satisfaction Questionnaire, Burnout Scale Inventory). Results: Burnout among men decreased along with increasing satisfaction with one's work and occupation, friends, relatives and acquaintances, sexuality, and increased due to greater satisfaction with one's housing status. Burnout among women decreased along with increasing satisfaction with one's health, free time and friends, relatives and acquaintances, and increased due to work at a setting other than a health care unit or educational center. Statistical analysis failed to reveal any significant differences with regard to the BSI domains and with regard to the overall burnout index as well as with regard to the assessment of satisfaction with life between female and male physiotherapists. Conclusions: Satisfaction with children, marriage and partnership, with one's work and occupation, interactions with friends, relatives and acquaintances and sexuality may contribute to reduction of burnout among men. Women who are satisfied with their children, family, health, free time and contacts with friends, relatives and acquaintances are less prone to burnout. Weak financial situation among women and deficiency of free time among men can induce burnout. Improving staff happiness may contribute to decreasing burnout.
\end{abstract}

Key words:

Burnout, Satisfaction, Gender, Physical therapy

Received: August 30, 2013. Accepted: March 17, 2014.

Corresponding author: M. Starczyńska, Institute of Physiotherapy, Jan Kochanowski University, Żeromskiego 5, 25-369 Kielce, Poland (e-mail: starm@ujk.edu.pl). 


\section{INTRODUCTION}

Phenomenon of burnout among health care professionals was described as physical and psychological exhaustion by Herbert Freudenberger in 1974 [1,2]. It was first observed among those working with mentally ill patients at intensive care units and at facilities for the terminally ill [3-5].

Burnout is more often experienced by those working with people who are ill, upset and anxious about their medical condition and its complications. This group includes medical doctors, nurses, psychologists, social workers, physiotherapists and volunteers [6-9].

Risk factors for burnout include: high demands in the workplace, little control over the outcomes of one's work, young age and the female gender [10-12]. Another recent study from Saudi Arabia shows that also age, female gender and, additionally, marital status, number of years in practice, sleep deprivation, presence of back pain and a negative effect of practice on family life are associated with burnout [13]. Results of the study conducted among nurses in China indicate that risk factors for burnout were also age (25-44 years), marital status (married), hospital department (emergency), position (primary title) and what is very rare: male gender [14]. The study from Portugal highlights some new risk factors that previously were not reported in the case of burnout (ethical decision making, temporary work contracts), and also protective ones (maintaining activity in other settings outside Intensive Care Units) [15].

With the obtained results of the study, the fact is that the relationship between gender and burnout is inconsistent [16].

Stress is a component of burnout, because burnout is a prolonged response to chronic emotional and interpersonal stressors at work. Stressors in medical practice can be classified as physical stressors, psychological stressors and sociological stressors. Physical stressors cause stress due to abnormal physical exertion, which is often complicated by under staffing, consecutive duty hours, poor staff scheduling and poor coordination between various departments leading to stress [17,18]. Psychological stress at work can be high in medical staff taking care of seriously ill and terminally ill patients [19,20]. For palliative care nurses psychological stress at work can be very high because of exposure to frequent deaths and family grieving [21]. The sociological stressors include pressure promotion, meeting expectations of superiors, achieving a stable position at work, acquiring social and professional status [22].

Stress may be experienced by everyone, but burnout affects those who begin their work with high expectations, motivations, lofty goals and derive their sense of importance from their work. Those who distance themselves from their jobs and do not have a high level of motivation experience work-related stress more often than burnout. According to the World Health Organization's definition, work-related stress is the response people may have when presented with work demands and pressures that are not matched to their knowledge and abilities and which challenge their ability to cope; while burnout is characteristic of those working with people and has to do with emotional demands. Stress does not always lead to burnout.

The research conducted by Fiabane in Italy was to identify the role of organizational and personal factors in predicting work engagement in health care workers, and to compare work engagement and occupational stress perceptions of health care professional categories. Work engagement is characterized by energy, involvement and professional efficacy and burnout is a condition, in the case of which medical staff experiences chronic fatigue, exhaustion, tiredness, anger and irritability on account of work stress. Significant predictors of energy were: workload, mental health and job satisfaction. On the other hand, predictors of work engagement included community, workload, mental health and job satisfaction. Results of this study show that, contrary to nurse aides with positive perceptions of work environment, physiotherapists had the highest 
levels of occupational stress and disengagement from their work [23].

Studies of medical professions have shown that it is possible to identify specific personal traits and environmental characteristics that are associated with job burnout. These characteristics include such symptoms as: headache, difficulty falling asleep, loss of appetite; psychological abnormalities such as depression and difficulties in interpersonal relations as well as behavioral problems such as taking more sick leave and negligence in the care provided to others [24].

Contact with patients and interpersonal communication skills are a critical factor of the work of physiotherapists. A physiotherapist works with other people who, importantly, face disease and ill health. Interaction with someone enduring a difficult experience, which a disease is, requires a multitude of skills and special predispositions. Interaction between a physiotherapist and other people, be it an individual, family or group, is a special type of social relation aiming at satisfying needs of relevance for life and health. The parties of the interaction influence one another and try to pursue their own values, different for each person, as well as values they share. The communicative task of a physiotherapist should be to reach mutual understanding and solicit activity of the patient serving their shared goals of improving, protecting or restoring health, and to persuade the patient to assume responsibility for these tasks. Interaction with other people plays a key role in the development of burnout and the level of satisfaction with life.

Bowling and colleagues in the meta-analysis found that the Organization-based self-esteem (OBSE) - a specific type of self-esteem, which describes the beliefs of employees about their values and competencies as members of an organization, is positively related to job satisfaction, commitment to the organization and work. The complexity of the task, autonomy, organizational commitment, organizational support and social support from managers and employees have an impact on job satisfaction and employee's satisfaction. A higher level of self-esteem in the organization is also associated with a lower likelihood of depression and ill health. The result was a stronger predictor (OBSE) than the overall self-esteem [25].

A review of the literature shows that the most effective actions aiming at prevention of burnout include: ethics of care in the relationship between medical staff and patients as well as their families, the preventive organizational strategies for burnout prevention [26], controlling work stressors, reducing personal strain, strengthening coping resources [27], high levels of occupational autonomy and support for work-life-balance from the Trust [28].

Happiness is one of the components of satisfaction with life [29]. Review of the literature indicates that happy people are financially successful and supported in relationships, enjoy better mental health and are more effective at work [30]. More importantly, happiness underlies these values, rather than being means to achieve these ends. Unfortunately, not much is known about how and why happiness produces so many positive effects [31]. Positive emotions are also associated with an improved self-esteem in the future [32]. It is known, however, that the component known as sexual satisfaction has a considerable influence on satisfaction with life. Sexual satisfaction accounts for the quality of life of married couples and a general sense of well-being and happiness [33-36].

\section{OBJECTIVES}

The primary aim of the study was to examine the effect of gender on satisfaction with life and burnout among active physiotherapists. The study's objective was also to identify determinants of satisfaction with life and burnout among women and men. The initial assumption was that low life satisfaction is associated with burnout and that the incidence of burnout in the profession of a physiotherapist is greater among women compared to man. 


\section{MATERIAL AND METHODS}

\section{Participants}

The study was carried out between April 2012 and January 2013. The survey was anonymous and voluntary and involved a group of 200 active physiotherapists working in health care units and educational centers in Poland. The sample was chosen randomly and incidentally. Professionally active physiotherapists were recruited from health care in 5 hospitals, 8 nursing homes, 8 clinics, 10 offices, 5 spas, and also from 3 educational institutions.

During the study 1200 sets of questionnaires were distributed. For further statistical analysis only 200 completed sets of questionnaires were considered. The response rate was $16.66 \%$, which can constitute a limitation of this study.

\section{Procedures}

Each respondent received a demographic data sheet and a set of self-rating questionnaires. Participation was anonymous and voluntary. The study procedure was described in detail to each participant before commencement of the study. The demographic data sheet was used to collect information about such variables as gender, age, educational status, length of service, position at work.

\section{Measures}

The following self-report questionnaires were used:

\section{Life Satisfaction Questionnaire (LSQ, based on FLZ)} by Frahrenberg, Myrtek, Schumacher and Brähler [37]. 2. Burnout Scale Inventory (BSI) by Steuden and Okła [38].

The Life Satisfaction Questionnaire (LSQ) was developed in 1998 and translated from German into Polish in 2000 by Januszewski and Zając [39].

The questionnaire is designed for individual and group investigations of healthy and ill adults. It consists of 70 items in a form of declarative sentences describing various aspects of life that represent potential sources of satisfaction.
Respondents evaluate to what degree each statement describes their lives and express this degree of agreement with the statement by marking 1 of 7 possible answers.

The questionnaire is composed of 10 domain scales with the same number (7) of items in each:

1. Subject's attitude to their children (SATC) - domain, which means that they derived the greatest joy from living with their children, their success at school and work, joys, hard work, influence and recognition of themselves as parents.

2. Marriage and partnership (MP) - applies only to people remaining in a stable relationship and concerns demands that a relationship places on the individual, shared undertakings, honesty, sincerity, understanding and security on the part of the partner as well as support and mutual readiness to provide help.

3. Friends, relatives, acquaintances (FRA) - this domain concerns interactions with friends and acquaintances, relatives and neighbors, including help and support on their part, external activity of the individual in tandem with others, involvement in social relations and the frequency of meeting people.

4. Self-assessment (SA) - includes external appearance, vitality, abilities and skills, previous achievements and trust in oneself, accounting for character differences and relations with others.

5. Sexuality $(\mathrm{S})$ - measures physical attractiveness, sexual performance and frequency of sexual contacts with the partner; assesses sexual relations and sincerity in talking about sex and the sexual "fit" with the partner.

6. Health $(\mathrm{H})$ - refers to bodily health, spiritual mood, general physical condition, mental ability, resistance to disease and frequency of pain and disease.

7. Housing status (HS) - refers to housing conditions, expenses and location, transport links and exposure to noise.

8. Work and occupation (W\&O) - evaluates position in the workplace, future prospects, achievements, possibility of promotion, atmosphere at work and work-related 
requirements, workload and any prospects for change that may be associated with one's occupation.

9. Free time (FT) - looks quantitatively and qualitatively at free time in the afternoon and at the weekends, leave from work, time for a hobby and time that can be devoted to one's closest relatives and modifications to the way of spending one's free time.

10. Financial status (FS) - domain, which looks at income, possession and economic standing and securing welfare for the family and oneself in old age.

The internal consistency coefficient (Cronbach's $\alpha$ ) was 0.95 in the analysis of responses of 60 participants for all the 70 questions.

The coefficients of reliability of individual domains according to the internal consistency method (Cronbach's $\alpha$ ), were as follows: $\mathrm{H} \alpha=0.92 ; \mathrm{W} \& \mathrm{O} \alpha=0.92 ; \mathrm{FS} \alpha=0.90$; $\mathrm{FT} \alpha=0.87 ; \mathrm{MP} \alpha=0.95 ; \mathrm{SATC} \alpha=0.90 ; \mathrm{SA} \alpha=0.91$; $\mathrm{S} \alpha=0.86 ; \mathrm{FRA} \alpha=0.86$; and $\mathrm{HS} \alpha=0.80$.

The Burnout Scale Inventory (BSI) was developed by Steuden and Okła in 1998. It is designed to study factors underlying burnout in professionally active individuals and work-related experiences. Some statements in the questionnaire refer to one's involvement in work and work-related fatigue.

The BSI comprises 66 items. Respondents indicate the level of their agreement with statements by marking one of 5 answers: yes, rather yes, I'm not sure, rather not, not. Based on the results of factorial analysis, the authors assigned the 66 statements to 5 domains:

1. Deterioration in emotional control (DEC) - including a sense of danger, anxiety, helplessness, loneliness, lack of natural energy to act and inability to enjoy life, increased irritability and impulsiveness.

2. Loss of personal involvement (LPI) - involving increased detachment from patients and their problems, a negative or cynical attitude to items and situations at work.

3. Narrowing of social contacts (NSC) - involves social and friendly contacts and the presence of dreams and interests.
4. Physical fatigue (PF) - loss of energy, chronic fatigue and unwillingness to work.

5. Reduced personal efficacy (RPE) - poor view of one's possibilities, concentration and organization of work, initiative, expected outcomes and individual incompetence. Each domain contains a different number of items.

There is no question conversion in the BSI. The overall score is a global index of intensity of job fatigue. This index is a raw score, while domain means are standardized according to a sten scale ('Standard Ten' scale). The reliability coefficients for the BSI domains according to the internal consistency method (Cronbach's $\alpha$ ), were as follows: $\mathrm{DEC} \alpha=0.59 ; \mathrm{LPL} \alpha=0.54 ; \mathrm{RPD} \alpha=0.49$; $\mathrm{NSC} \alpha=0.49 ;$ and $\mathrm{PF} \alpha=0.52$.

\section{Statistical design}

The raw data were subjected to a statistical analysis. The normality of distributions for measurable data was assessed with the Shapiro-Wilk W test. The Mann-Whitney $\mathrm{U}$ test was used to compare 2 independent samples, while the Kruskal-Wallis test was used to compare more than 2 groups. Correlations between variables were assessed with the Spearman's correlation analysis (R).

Step-wise regression analysis was used to assess the percentage of predicted variance and identify factors accounting for the work fatigue index (OI), with the exclusion criterion for $\mathrm{F}$ at $\mathrm{p}>0.01$. The results of regression analysis were presented as values of the adjusted coefficient of determination $\left(\mathrm{R}^{2}\right)$, which corresponds to the percentage of the dependent variable predicted by the independent variables in the model, and the values of coefficients of parameters of the model $(\beta)$. The values and significance levels of $t$ test statistics (testing the significance of each parameter of the equation) were also given as were the values and significance levels of the $\mathrm{F}$ test, which tests the values of all the parameters collectively.

Analysis of variance is an irreplaceable tool testing the significance of all variables in the multiple regression 
analysis. Analysis of variance as part of regression analysis uses and processes all important information associated with the model being constructed.

The significance level, indicating statistically significant differences or correlations, was set at $p<0.05$. The data base and statistical analyses were performed with Statistica 10.0 (StatSoft, Polska).

\section{RESULTS}

\section{Characteristics of the study group}

The sample comprised a group of 200 physiotherapists aged 20-73 years, of whom $72 \%(\mathrm{~N}=144)$ were women and $28 \%(\mathrm{~N}=56)$ were men. The small group of men can be an important limitation of the study.

The mean age of the respondents was $36.10 \pm 10.03$ years. The respondents under 30 years of age accounted for $31.5 \%$ of the study group $(\mathrm{N}=63), 34 \%(\mathrm{~N}=68)$ of the respondents were between 30 and 40 years old, $22 \%$ $(\mathrm{N}=44)$ - were between the ages of 41 and 50 years and $12.5 \%(\mathrm{~N}=25)$ - were more than 50 years old.

With regard to educational status, the respondents mostly held a BA degree in physiotherapy and worked as junior assistants (39.5\%) (Table 1).

\section{Levels of burnout among physiotherapists (BSI)}

The statistical analysis failed to detect significant differences with respect to the overall burnout index (OI) between women and men $(Z=0.02 ; p=0.99)$ as well as with respect to the subscales DEC $(Z=-0.29 ; p=0.78)$, LPI $(Z=-0.62 ; 0.53)$, RPE $(Z=0.10 ; p=0.92)$ and $\operatorname{NSC}(Z=-0.05 ; p=0.96)$ and PF $(Z=0.29 ; p=0.77)$ (Table 2).

\section{Life satisfaction index (LSQ)}

The results show that men demonstrated non-significantly greater satisfaction with life with regard to most subscales, except for the subject's attitude to their children
Table 1. The socio-economic characteristics of the sample

\begin{tabular}{|c|c|c|}
\hline \multirow[t]{2}{*}{ Variable } & \multicolumn{2}{|c|}{$\begin{array}{c}\text { Respondents } \\
(\mathrm{N}=200)\end{array}$} \\
\hline & $\mathrm{n}$ & $\%$ \\
\hline \multicolumn{3}{|l|}{ Age (years) } \\
\hline$<30$ & 63 & 31.50 \\
\hline $30-40$ & 68 & 34.00 \\
\hline $41-50$ & 44 & 22.00 \\
\hline$>50$ & 25 & 12.50 \\
\hline \multicolumn{3}{|l|}{ Gender } \\
\hline women & 144 & 72.00 \\
\hline men & 56 & 28.00 \\
\hline \multicolumn{3}{|l|}{ Educational status } \\
\hline degree of PT technician & 45 & 22.50 \\
\hline BA degree in PT & 42 & 21.00 \\
\hline MA in PT & 84 & 42.00 \\
\hline specialization in PT & 10 & 5.00 \\
\hline $\mathrm{PhD}$ degree & 19 & 9.50 \\
\hline \multicolumn{3}{|l|}{ Position } \\
\hline junior assistant & 79 & 39.50 \\
\hline assistant & 23 & 11.50 \\
\hline senior assistant & 29 & 14.50 \\
\hline junior technician & 17 & 8.50 \\
\hline technician & 20 & 10.00 \\
\hline senior technician & 32 & 16.00 \\
\hline \multicolumn{3}{|l|}{ Type of organization } \\
\hline hospital & 69 & 34.50 \\
\hline nursing home & 33 & 16.50 \\
\hline clinic & 13 & 6.50 \\
\hline office & 16 & 8.00 \\
\hline spa center & 22 & 11.00 \\
\hline educational institution & 47 & 23.50 \\
\hline
\end{tabular}

PT - physical therapist; BA - bachelor of art; MA - master of art; $\mathrm{PhD}$ - doctor of philosophy.

subscale and the friends, relatives and acquaintances subscale. The statistical analysis failed to detect significant differences with regard to the subscales: $\mathrm{LS}(\mathrm{Z}=-1.18$; $\mathrm{p}=0.24), \mathrm{H}(\mathrm{Z}=-1.69 ; \mathrm{p}=0.09), \mathrm{W} \& \mathrm{O},(\mathrm{Z}=-1.25$; 
Table 2. Burnout Scale Inventory (BSI) domain scores by gender

\begin{tabular}{lcccccccc}
\hline \multirow{2}{*}{ Domain } & \multicolumn{3}{c}{ Women $(\mathrm{N}=144)$} & \multicolumn{3}{c}{ Men $(\mathrm{N}=56)$} & \multicolumn{2}{c}{ Statistical analysis } \\
\cline { 2 - 8 } & $\mathrm{M}$ & $\mathrm{Me}$ & $\mathrm{SD}$ & $\mathrm{M}$ & $\mathrm{Me}$ & $\mathrm{SD}$ & $\mathrm{Z}$ & $\mathrm{p}$ \\
\hline DEC & 35.46 & 30.00 & 15.17 & 34.96 & 32.00 & 13.60 & -0.29 & 0.78 \\
LPI & 25.88 & 23.00 & 9.79 & 25.61 & 25.00 & 7.82 & -0.62 & 0.53 \\
RPE & 19.82 & 18.00 & 6.95 & 19.73 & 18.50 & 6.89 & 0.10 & 0.92 \\
NSC & 15.94 & 14.00 & 6.25 & 16.29 & 14.00 & 6.77 & -0.05 & 0.96 \\
PF & 17.49 & 17.00 & 6.16 & 17.54 & 16.00 & 6.62 & 0.29 & 0.77 \\
OI & 114.59 & 107.50 & 38.41 & 114.13 & 109.50 & 36.71 & 0.02 & 0.99 \\
\hline
\end{tabular}

DEC - deterioration in emotional control; LPI - loss of personal involvement; RPE - reduced personal efficacy; NSC - narrowing of social contacts; $\mathrm{PF}$ - physical fatigue; OI - overall burnout index;

$\mathrm{M}$ - mean; Me - median; SD - standard deviation.

Z - Mann-Whitney U test.

Table 3. Life Satisfaction Questionnaire (LSQ) domain scores by gender

\begin{tabular}{lrrrrrrrc}
\hline \multirow{2}{*}{ Domain } & \multicolumn{3}{c}{ Women $(\mathrm{N}=144)$} & \multicolumn{3}{c}{ Men $(\mathrm{N}=56)$} & \multicolumn{2}{c}{ Statistical analysis } \\
\cline { 2 - 8 } & $\mathrm{M}$ & $\mathrm{Me}$ & $\mathrm{SD}$ & $\mathrm{M}$ & $\mathrm{Me}$ & $\mathrm{SD}$ & $\mathrm{Z}$ & $\mathrm{p}$ \\
\hline LS & 316.30 & 326.00 & 65.49 & 334.29 & 328.50 & 60.65 & -1.18 & 0.24 \\
$\mathrm{H}$ & 35.34 & 36.00 & 6.74 & 37.04 & 38.00 & 5.82 & -1.69 & 0.09 \\
W\&O & 32.23 & 33.00 & 7.78 & 33.71 & 35.00 & 9.13 & -1.25 & 0.21 \\
FS & 24.72 & 24.50 & 8.38 & 27.54 & 27.50 & 9.21 & -1.89 & 0.06 \\
FT & 29.01 & 29.00 & 8.49 & 27.39 & 29.00 & 9.59 & 0.84 & 0.40 \\
MP & 39.28 & 41.00 & 7.14 & 39.53 & 41.00 & 7.69 & -0.30 & 0.77 \\
SATC & 42.00 & 43.00 & 5.98 & 41.32 & 42.00 & 5.72 & 0.74 & 0.46 \\
SA & 36.44 & 37.50 & 6.43 & 37.21 & 38.00 & 6.43 & -0.73 & 0.47 \\
S & 36.22 & 38.00 & 8.25 & 38.42 & 39.00 & 6.40 & -1.52 & 0.13 \\
FRA & 37.17 & 38.00 & 5.70 & 36.42 & 36.00 & 6.32 & 0.82 & 0.41 \\
HS & 34.78 & 35.00 & 6.17 & 35.87 & 36.00 & 6.88 & -1.14 & 0.25 \\
\hline
\end{tabular}

LS - overall life satisfaction; H - health; W\&O - work and occupation; FS - financial status; FT - free time; MP - marriage and partnership; SATS - subject's attitude to their children; SA - self-assessment; S - sexuality; FRA - friends, relatives, acquaintances; HS - housing status.

Other abbreviations as in Table 2.

$p=0.21), F S(Z=-1.89 ; p=0.06), F T(Z=0.84$

$\mathrm{p}=0.40), \operatorname{MP}(\mathrm{Z}=-0.30 ; \mathrm{p}=0.77)$, SATC $(\mathrm{Z}=0.74$

$p=0.46), S A(Z=-0.73 ; p=0.47), S(Z=-1.52$;

$\mathrm{p}=0.13)$, FRA $(\mathrm{Z}=0.82 ; \mathrm{p}=0.41)$ and $\mathrm{HS}(\mathrm{Z}=-1.14$;

$\mathrm{p}=0.25)($ Table 3$)$.

The statistical analysis did not reveal any significant differences in the assessment of satisfaction with life between the male and female physiotherapists $(\mathrm{p}>0.05)$.
The impact of selected variables on burnout intensity

The step-wise progressive regression analysis for the variable OI (overall burnout index) included the following variables: the LSQ domains, gender, age, length of service, workplace setting and position (as variables coded 0 or 1 , where 1 referred to a specific workplace setting or position). The model accounting for variation in OI (burnout) comprised the variables: health $(\mathrm{H})$, workplace 
setting - health care setting; friends, relatives, acquaintances (FRA), work and occupation, (W\&O) and housing status (HS) (Table 1), while the remaining variables were not incorporated. The structural parameters of the model with the intercept are highly significant $(\mathrm{p}<0.0001)$. The variable $\mathrm{H}$, which entered the model as the first variable, predicted as much as $33 \%\left(\mathrm{R}^{2}=0.33 ; \mathrm{p}=0.000001\right)$ of the variance in OI. It was followed by the variable workplace setting - health care setting $\left(\mathrm{R}^{2}=0.24 ; \mathrm{p}=0.00003\right)$, FRA $\left(\mathrm{R}^{2}=0.26 ; \mathrm{p}=0.00005\right), \mathrm{W} \& \mathrm{O}\left(\mathrm{R}^{2}=0.24 ; \mathrm{p}=0.0002\right)$ and HS $\left(\mathrm{R}^{2}=0.13 ; \mathrm{p}=0.03\right)$. The model of regression predicted $50 \%$ of the variance in the variable OI (Table 4). Further statistical analysis involved a regression analysis for the variable OI among men. The analysis included the same variables as above. The resulting model predicted $56 \%$ of the variance in the intensity of burnout. The following variables consecutively entered the model: $\mathrm{W} \& \mathrm{O}$ $\left(\mathrm{R}^{2}=0.47 ; \mathrm{p}=0.0001\right)$, FRA $\left(\mathrm{R}^{2}=0.43 ; \mathrm{p}=0.0006\right), \mathrm{HS}$ $\left(R^{2}=0.25 ; p=0.03\right)$ and $S\left(R^{2}=0.26 ; p=0.04\right)$.
The analysis of variance showed that, of the overall sum of squares of the variable OI, $44 \%$ of the variance was not predicted by regression. The results indicate that burnout among men $\left(\mathrm{OI}_{\mathrm{M}}\right)$ decreased along with increasing satisfaction with one's work and occupation, friends, relatives and acquaintances, sexuality, and increased along with greater satisfaction with one's housing status (Table 5).

Further statistical analysis involved a regression analysis for the variable OI among women. The analysis included the same variables as the analysis for the entire group. The resulting model predicted $44 \%$ of the variance in the intensity of burnout among women. The following variables consecutively entered the model: $\mathrm{H}\left(\mathrm{R}^{2}=0.35\right.$; $\mathrm{p}=0.00002)$, FT $\left(\mathrm{R}^{2}=0.23 ; \mathrm{p}=0.003\right)$, workplace setting - other than health care unit or educational center $\left(\mathrm{R}^{2}=0.23 ; \mathrm{p}=0.002\right)$ and FRA $\left(\mathrm{R}^{2}=0.18 ; \mathrm{p}=0.02\right)$.

The analysis of variance showed that, of the overall sum of squares of the variable OI, $56 \%$ of the variance is not predicted by regression.

Table 4. Regression model for variable OI (overall burnout index)

\begin{tabular}{lrcrrrc}
\hline \multicolumn{1}{c}{ Factor } & \multicolumn{1}{c}{$\beta$} & SE of $\beta$ & $\mathrm{b}$ & $\mathrm{SE}$ of b & \multicolumn{1}{c}{$\mathrm{t}$} & $\mathrm{p}$ \\
\hline Health & -0.339 & 0.065 & -1.948 & 0.374 & -5.208 & 0.000001 \\
Workplace setting - health care setting & 0.238 & 0.055 & 17.121 & 3.962 & 4.322 & 0.000030 \\
Friends, relatives, acquaintances & -0.261 & 0.063 & -1.567 & 0.377 & -4.155 & 0.000050 \\
Work \& occupation & -0.235 & 0.061 & -1.011 & 0.263 & -3.843 & 0.000200 \\
Housing status & 0.132 & 0.059 & 0.728 & 0.327 & 2.226 & 0.030000 \\
\hline
\end{tabular}

$\beta$ - standardized coefficient; SE - standard error; $\mathrm{b}$ - regression coefficient; $\mathrm{t}$ - $\mathrm{t}$-test; $\mathrm{R}^{2}$ - coefficient of determination.

$\mathrm{R}^{2}$ adjusted $=0.50 ; \mathrm{F}=35.17 ; \mathrm{p}<0.00001$.

Table 5. Regression model for variable $\mathrm{OI}_{\mathrm{M}}$ (overall burnout index for men)

\begin{tabular}{lcccccc}
\hline \multicolumn{1}{c}{ Factor } & $\beta$ & SE of $\beta$ & $\mathrm{b}$ & $\mathrm{SE}$ of b & $\mathrm{t}$ & $\mathrm{p}$ \\
\hline Friends, relatives, acquaintances & -0.470 & 0.113 & -2.680 & 0.642 & -4.174 & 0.0001 \\
Work \& occupation & -0.430 & 0.118 & -1.672 & 0.457 & -3.660 & 0.0006 \\
Sexuality & -0.245 & 0.107 & -1.400 & 0.613 & -2.284 & 0.0300 \\
Housing status & 0.264 & 0.123 & 1.381 & 0.646 & 2.140 & 0.0400 \\
\hline
\end{tabular}

$\mathrm{R}^{2}$ adjusted $=0.56 ; \mathrm{F}=15.42 ; \mathrm{p}<0.00001$.

Other abbreviations as in Table 4. 
Table 6. Regression model for variable $\mathrm{OI}_{\mathrm{W}}$ (overall burnout index for women)

\begin{tabular}{lcccccc}
\hline \multicolumn{1}{c}{ Factor } & $\beta$ & SE of $\beta$ & $\mathrm{b}$ & $\mathrm{SE} \mathrm{of} \mathrm{b}$ & $\mathrm{t}$ & $\mathrm{p}$ \\
\hline Health & -0.353 & 0.080 & -1.993 & 0.452 & -4.406 & 0.00002 \\
Free time & -0.225 & 0.074 & -0.925 & 0.303 & -3.055 & 0.00300 \\
$\begin{array}{l}\text { Workplace setting other than a health } \\
\text { care or educational center }\end{array}$ & 0.225 & 0.071 & 7.990 & 2.525 & 3.164 & 0.00200 \\
Friends, relatives, acquaintances & -0.177 & 0.075 & -1.082 & 0.455 & -2.377 & 0.02000 \\
\hline
\end{tabular}

$\mathrm{R}^{2}$ adjusted $=0.44 ; \mathrm{F}=24.75 ; \mathrm{p}<0.00001$.

Other abbreviations as in Table 4.

The results indicate that burnout among women $\left(\mathrm{OI}_{\mathrm{w}}\right)$ decreased along with increasing satisfaction with health, free time and friends, relatives and acquaintances, and increased in workplace settings other than a health care unit or educational center (Table 6).

\section{DISCUSSION}

The aim of this study was to identify determinants of satisfaction with life and burnout among women and men. The statistical analysis in this study failed to reveal any significant differences with regard to the BSI domains and with regard to the overall burnout index between female and male physiotherapists, and also, did not reveal any significant differences in terms of the assessment of satisfaction with life between male and female physiotherapists.

Determinants of high life satisfaction were: family, offspring, a partnership in relation to both women and men. Financial situation definitely had the greatest impact on reducing life satisfaction of women. Among men the greatest impact on reducing life satisfaction was insufficient amount of free time.

Pre-adopted hypotheses were not confirmed in this study. The sample comprised a group of 200 physiotherapists of whom $72 \%$ were women. Small group of men could be an important limitation of the study.

Data from the study show that burnout among men decreased along with increasing satisfaction with one's work and occupation, friends, relatives and acquaintances, sexuality, and increased due to greater satisfaction with one's housing status.
According to this study, burnout among women decreased along with increasing satisfaction with one's health, free time and friends, relatives and acquaintances, and increased due to work at a setting other than a health care unit or educational center.

These results are partially confirmed by literature.

The literature indicates that burnout among men in medical professions more often manifests itself as depersonalization, while in the case of women the prevailing symptom is emotional exhaustion [40]. In the literature, women appear to be more prone to developing burnout than men $[41,42]$. The present study did not confirm those earlier reports as no statistically significant differences were noted between men and women in the burnout and life satisfaction scales. The scores for the BSI domains of reduction of emotional control and loss of personal involvement were also equally high for men and women.

At the same time, it is certain that the symptoms of burnout among men and women are somewhat different [43], the reason being differences between the genders conditioned by the process of socialization. Boys and men are stimulated to be independent and not to show their weaknesses, which is associated with suppression of problems and lack of externalisation of one's problems [44], which is not the women's case.

However, a Swedish study, producing surprising results, showed a greater incidence of burnout among women working "with objects" as opposed to those working "with 
people". The women most prone to developing burnout came from families with low socio-economic status [45]. The 2010 study in Cyprus showed that gender significantly influenced the development of burnout among physiotherapists, which was seen more frequently among women. However, the strongest determinants of emotional burnout were poor pay and stress [46].

Notably, the lack of satisfaction was most strikingly expressed in the financial status domain. The remuneration of physiotherapists is not sufficient to satisfy their basic needs and support the family. Dissatisfaction is also caused by the awareness of a disparity between pay rates on the one hand, and demands of the profession as well as individual effort put into the work, on the other. Many papers in the literature point to socio-economic status and pay levels as risk factors of burnout among women [45]. The Australian study of nurses proved that a high level of satisfaction significantly reduces the possibility of stress, depression, which in turn can lead to burnout [47]. Australian emergency physicians despite the great threat of burnout were very satisfied with their jobs [48].

The study conducted in Israel aimed at quantification of the satisfaction with life and work-life satisfaction of mental health staff at a psychiatric center. The highest levels of happiness were reported by psychologists and social workers. The highest levels of work as a calling were reported by psychiatrists, followed by psychologists and social workers [49].

In summary, it should be stated that personal development and, consequently, satisfaction with life and continuous improvement of an individual's level of functioning are only possible when the individual is able to look ahead and to become involved in activities so far-reaching that they are worth living for.

\section{Limitation of the study}

The analysis showed that the BSI scale had a high reliability, with an internal consistency coefficient (Cronbach's $\alpha$ ) of 0.97. BSI subscales alpha coefficients are very low and this can be an important limitation of this study.

Another limitation of this study is the low response rate (16.66\%), which strongly limits the generalizability of the results. It may have been caused by working under time pressure. Physiotherapists often did not have the opportunity to return a fully completed survey because of too many duties to perform during working hours. Another reason may be a reluctance to fulfill papers because of the need to complete documentation of patients and weariness of written work.

\section{CONCLUSIONS}

In conclusion, satisfaction with children, marriage and partnership, with one's work and occupation, interactions with friends, relatives and acquaintances, as well as sexuality may contribute to reduction in burnout among men. Women who are satisfied with their children, family, health, free time and contacts with friends, relatives and acquaintances are less prone to burnout. This paper also shows that weak financial situation among women and deficiency of free time among men can induce burnout. Improving staff happiness may contribute to decreasing counter burnout.

\section{REFERENCES}

1. Freudenberger HJ. Staff Burn-out. J Soc Issues. 1974;30: 159-65, http://dx.doi.org/10.1111/j.1540-4560.1974.tb00706.x.

2. Kraft U. Burned out: Your job is extremely fulfilling. It is also extremely demanding - and you feel overwhelmed. You are not alone. Sci Am Mind. 2006;1:29-33.

3. Burke RJ, Greenglass ER. Hospital restructuring, work-family conflict and psychological burnout among nursing staff. Health Psychol. 2001;32:126-38.

4. Keane A, DuCette J, Adler C. Stress in I.C.U and non I.C.U nurses. Nurs Res. 1985;34:231-6, http://dx.doi. org/10.1097/00006199-198507000-00012. 
5. Gray-Toff P, Anderson J. Sources of stress in nursing terminal patients in a hospice. Omega. 1986;17:27-39.

6. Karanikola M, Papathanassoglou E, Giannakopoulou M, Koutroubas A. Pilot exploration of the association between self-esteem and professional satisfaction in Hellenic Hospital nurses. J Nurs Manag. 2007;15:78-90, http://dx.doi. org/10.1111/j.1365-2934.2006.00673.x.

7. Jimmieson NL. Employee reactions to behavioral control under conditions of stress: The moderating role of selfefficacy. Work Stress. 2000;14(3):262-80, http://dx.doi. org/10.1080/02678370010015343.

8. Soler JK, Yaman H, Esteva M, Dodds F, Spiridonova Asenova R, Katic M, et al. Burnout in European family doctors: The EGPRN Study. Fam Pract. 2008;25:245-65, http:// dx.doi.org/10.1093/fampra/cmn038.

9. Demir A, Ulosoy M, Ulosoy MF. Investigation of factors influencing burnout levels in professional and private lives of nurses. Int J Nurs Stud. 2003;40:807-27, http://dx.doi. org/10.1016/S0020-7489(03)00077-4.

10. Bakker AB, Demerouti E, Schaufeli WB. Validation of the maslach burnout inventory - general survey: An internet study. Anxiety Stress Coping. 2002;15:245-60, http://dx.doi. org/10.1080/1061580021000020716.

11. Khanna R, Khanna R. Is medicine turning into unhappy profession? Indian J Occup Environ Med. 2013;17(1):2-6, http://dx.doi.org/10.4103/0019-5278.116363.

12. Hildingsson I, Westlund K, Wiklund I. Burnout in Swedish midwives. Sex Reprod Health. 2013;4(3):87-91, http:// dx.doi.org/10.1016/j.srhc.2013.07.001.

13. Aldrees TM, Aleissa S, Zamakhshary M, Badri M, SadatAli M. Physician well-being: prevalence of burnout and associated risk factors in a tertiary hospital, Riyadh, Saudi Arabia. Ann Saudi Med. 2013;33(5):451-6.

14. Yao Y, Yao W, Wang W, Li H, Lan Y. Investigation of risk factors of psychological acceptance and burnout syndrome among nurses in China. Int J Nurs Pract. 2013;19(5):530-8, http://dx.doi.org/10.1111/ijn.12103.
15. Teixeira C, Ribeiro O, Fonseca AM, Carvalho AS. Burnout in intensive care units - A consideration of the possible prevalence and frequency of new risk factors: A descriptive correlational multicenter study. BMC Anesthesiol. 2013;13(1):38, http://dx.doi.org/10.1186/1471-2253-13-38.

16. Maslach C, Schaufeli WB, Leiter MP. Job burnout. Ann Rev Physiol. 2001;52:397-422, http://dx.doi.org/10.1146/annurev. psych.52.1.397.

17. McIntosh B, Sheppy B. Effects of stress on nursing integrity. Nurs Stand. 2013;27(25):35-9, http://dx.doi.org/10.7748/ ns2013.02.27.25.35.e7199.

18. Sembajwe G, Tveito TH, Hopcia K, Kenwood C, O’Day ET, Stoddard AM, et al. Psychosocial stress and multi-site musculoskeletal pain: A cross-sectional survey of patient care workers. Workplace Health Saf. 2013;61(3):117-25.

19. Moody K, Kramer D, Santizo RO, Magro L, Wyshogrod D, Ambrosio J, et al. Helping the helpers: Mindfulness training for burnout in pediatric oncology a pilot program. J Pediatr Oncol Nurs. 2013;30(5):275-84, http://dx.doi. org $/ 10.1177 / 1043454213504497$.

20. Udo C, Danielson E, Henoch I, Melin-Johansson C. Surgical nurses' work-related stress when caring for severely ill and dying patients in cancer after participating in an educational intervention on existential issues. Eur J Oncol Nurs. 2013;17(5):546-53, http://dx.doi.org/10.1016/ j.ejon.2013.02.002.

21. Yoon SL, Kim JH. Job-related stress, emotional labor, and depressive symptoms among Korean nurses. J Nurs Scholarsh. 2013;45(2):169-76, http://dx.doi.org/10.1111/jnu.12018.

22. Seleghim MR, Mombelli MA, de Oliveira ML, Waidman MA. Stress symptoms in female nurses working in emergency rooms. Rev Gaucha Enferm. 2012;33(3):165-73, http://dx.doi.org/10.1590/S1983-14472012000300022.

23. Fiabane E, Giorgi I, Sguazzin C, Argentero P. Work engagement and occupational stress in nurses and other healthcare workers: The role of organisational and personal factors. J Clin Nurs. 2013;22(17-18):2614-24, http://dx.doi. org/10.1111/jocn.12084. 
24. Kania M, Meyer B, Ebersole K. Personal and environmental characteristics predicting burnout among certified athletic trainers at national collegiate athletic association institutions. J Athl Train. 2009;44(1):58-66.

25. Bowling NA, Eschleman KJ, Wang Q, Kirkendall C, Alarcon G. A meta-analysis of the predictors and consequences of organization-based self esteem. J Occup Organ Psychol. 2010;83(3):601-26, http://dx.doi.org/10.1348/ 096317909X454382.

26. Fonseca A, Pereira S, Carvalho AS. Burnout in nurses working in Portuguese palliative care teams: A mixed methods study. Int J Palliat Nurs. 2012;18(8):373-8.

27. Wu S, Li H, Zhu W, Lin S, Chai W, Wang X. Effect of work stressors, personal strain, and coping resources on burnout in Chinese medical professionals: A structural equation model. Ind Health. 2012;50(4):279-87.

28. Yoshida Y, Sandall J. Occupational burnout and work factors in community and hospital midwives: A survey analysis. Midwifery. 2013;29(8):921-6, http://dx.doi.org/10.1016/j.midw. 2012.11.002.

29. Cohn M, Fredrickson B, Brown S, Mikels J, Conway A. Happiness unpacked: positive emotions increase life satisfaction by building resilience. Emotion. 2009;9(3):361-8, http:// dx.doi.org/10.1037/a0015952.

30. Lyubomirsky SL, King L, Diener E. The benefits of frequent positive affect: Does happiness lead to success? Psychol Bull. 2005;14:803-55, http://dx.doi.org/10.1037/00332909.131.6.803.

31. Fredrickson BL. The role of positive emotions in positive psychology. Am Psychol. 2001;56(3):218-26.

32. Diener E, Lucas RE, Scollon CN. Beyond the hedonic treadmill: Revisions to the adaptation theory of well-being. Am Psychol. 2006;61:305-14.

33. Davison SL, Bell RJ, LaChina M, Holden SM, Davis SR. The relationship between self-reported sexual satisfaction and general well-being in women. J Sex Med. 2009;6:2690-7, http://dx.doi.org/10.1111/j.1743-6109.2009.01406.x.
34. Dunn K, Croft P, Hackett G. Satisfaction in the sex life of a general population sample. J Sex Marital Ther. 2000;26:141-51, http://dx.doi.org/10.1080/009262300278542.

35. Sprecher S. Sexual satisfaction in premarital relationships: Associations with satisfaction, love, commitment, and stability. J Sex Res. 2002;39:190-6, http://dx.doi. org/10.1080/00224490209552141.

36. Rosen R, Brown C, Leiblum S, Meston CM, Shabsigh R. The female sexual function index (FSFI): A multidimensional self-report instrument for the assessment of female sexual function. J Sex Marital Ther. 2000;26:191-208, http:// dx.doi.org/10.1080/009262300278597.

37. Fahrenberg J, Myrtek M, Schumacher J, Brähler E. [Life Satisfaction Questionnaire (LSQ)]. Handanweisung, Göttingen: Hogrefe; 2000. German.

38. Steuden S, Okła W. Temporary textbook Burnout Scale Force - SWS. Experimental Edition. Lublin: Catholic University of Lublin; 1998.

39. Chodkiewicz J. [Treatment of alcohol dependence: anxiety and depression and personal resources. Alcoholism and drug addiction]. Alkohol Narkom. 2010;23:(3):201-16. Polish.

40. Houkes I, Winants Y, Twellaar M, Verdonk P. Development of burnout over time and the causal order of the three dimensions of burnout among male and female GPs. A threewave panel study. BMC Public Health. 2011;11:240-6, http:// dx.doi.org/10.1186/1471-2458-11-240.

41. Bakker AB, Demerouti E, Schaufeli WB. Validation of the Maslach burnout inventory - general survey: An internet study. Anxiety Stress Coping. 2002;15:245-60, http://dx.doi. org/10.1080/1061580021000020716.

42. Emmerik IJH, Euwema MC. At risk of burnout: Gender and faculty differences within academia. In: Jonge $\mathrm{J}$ de, Vlerick P, Büssing A, Schaufeli WB, editors. Organisational psychology and health care. At the start of a new millennium. München: Rainer Hampp Verlag; 2001. p. 123-38.

43. Maslach C, Leiter MP. Early predictors of job burnout and engagement. J Appl Psychol. 2008;93:498-512, http://x.doi. org/10.1037/0021-9010.93.3.498. 
44. Hammarström A. A tool for developing gender research in medicine: Examples from the medical literature on work life. Gender Med. 2007;4(Suppl):S123-32, http://dx.doi. org/10.1016/S1550-8579(07)80053-2.

45. Norlund S, Reuterwall C, Höög J, Lindahl B, Janlert U, Birgander L. Burnout, working conditions and gender results from the northern Sweden MONICA Study. BMC Public Health. 2010;10:326, http://dx.doi.org/10.1186/14712458-10-326.

46. Pavlakis A, Raftopoulos V, Theodorou M. Burnout syndrome in Cypriot physiotherapists: A national survey. BMC Health Serv Res. 2010;10:63, http://dx.doi.org/10.1186/14726963-10-63.
47. Hegney DG, Craigie M, Hemsworth D, Osseiran-Moisson R, Aoun S, Francis K, et al. Compassion satisfaction, compassion fatigue, anxiety, depression and stress in registered nurses in Australia: study 1 results. J Nurs Manag. Forthcoming 2014, http://dx.doi.org/10.1111/jonm.12160.

48. Arora M, Asha S, Chinnappa J, Diwan AD. Review article: Burnout in emergency medicine physicians. Emerg Med Australas. 2013;25(6):491-5, http://dx.doi.org/10.1111/17426723.12135 .

49. Baruch Y, Swartz M, Sirkis S, Mirecki I, Barak Y. Staff happiness and work satisfaction in a tertiary psychiatric center. Occup Med (Lond). 2013;63(6):442-4, http://dx.doi. org/10.1093/occmed/kqt087.

This work is available in Open Access model and licensed under a Creative Commons Attribution-NonCommercial 3.0 Poland License - http://creativecommons.org/ licenses/by-nc/3.0/pl/deed.en. 